\title{
El impacto de la reelección municipal inmediata, en la reforma constitucional de 2014, para el gobierno municipal y la democracia nacional
}

\author{
The Impact of Consecutive Term Municipal \\ Reelection, as Stated in the 2014 Constitutional \\ Reform, on Municipal Government \\ and National Democracy
}

\section{Eduardo de Jesús Castellanos Hernández}

\section{Sumario:}

I. Introducción

II. La reelección municipal inmediata en Latinoamérica

III. La historia constitucional nacional

IV. La no reelección municipal consecutiva en México

V. El Pacto por México

VI. El proceso legislativo de la reforma de 2014

VII. La reforma de 2014

VIII. Las leyes generales

IX. Reflexión final

X. Bibliografía

* Investigador en el Instituto de Investigaciones Jurídicas de la UNAM. 


\section{Resumen:}

En esta contribución se analiza la reelección municipal inmediata en la reforma constitucional de 10 de febrero de 2014, a la luz de la evolución histórica de las leyes que regulan las elecciones municipales en el contexto del sistema político mexicano, así como desde la perspectiva de las diferentes teorías políticas, el derecho comparado y el sistema electoral. Con ello, el autor pretende analizar, en un horizonte prospectivo, si la introducción de la figura coadyuvará a incrementar la eficacia y eficiencia en la gestión de los asuntos públicos municipales.

\begin{abstract}
:
In this contribution I analyze consecutive term reelection at the municipal level as introduced in the constitutional reform of February 10th, 2014. I present this analysis in light of the historical evolution of the law that regulates municipal elections within the Mexican political system as well as from the point of views given by different political theories, comparative law and the electoral system. With this, the author seeks to provide a prospective analysis on whether introducing this reform will increase efficacy and efficiency in managing public matters at the municipal level.
\end{abstract}

Palabras clave: reelección municipal, sistema político, sistema electoral, sistema de partidos, sistema de gobierno, Pacto por México, reforma 2014, leyes generales.

Key words: municipal reelection, political system, electoral system, political parties, government, Pacto por Mexico, 2014 reform, general law. 


\section{Introducción}

El estudio comparado de los sistemas político electorales habitualmente se centra en el orden nacional; en ocasiones se llega al nivel subnacional entendido como el gobierno de las entidades federativas o estados de las repúblicas federales, ${ }^{1}$ pero rara vez esos estudios llegan al nivel municipal; incluso el estudio de las elecciones por usos y costumbres de autoridades municipales es tan reciente como la reforma constitucional de $2001^{2}$ aunque se practique desde antes de la conquista española. ${ }^{3}$ Por ejemplo, los dos manuales de IDEA Internacional para el diseño de sistemas electorales ${ }^{4}$ enfocan su atención en los sistemas electorales para la integración de parlamentos nacionales. Ciertamente, como sucede en México, esos sistemas electorales nacionales definen el diseño de los sistemas electorales subnacionales, incluso municipales, como es el caso de la representación proporcional en el orden municipal de gobierno. De ahí la necesidad e importancia de adoptar como objeto de estudio específico el orden municipal, el cual desde luego no puede ser analizado de manera aislada, sin tener en cuenta los órdenes estatal y federal.

El impacto de la reelección municipal inmediata o elección consecutiva como parte de la reforma constitucional del 10 de febrero de 2014 puede ser visto al interior de la reforma constitucional en sí misma, pero también más allá del universo político electoral que entraña el conjunto de reformas a la Constitución publicadas en esa fecha, es decir, en el funcionamiento del sistema político (sistema electoral, sistema de partidos y sistema de gobierno) y en la sociedad en general.

En nuestro país existen 2440 municipios ${ }^{5}$ cuyas atribuciones en la prestación de los servicios públicos previstos en el artículo 115 de la Constitución general de la República corresponden a las materias siguientes: a) agua potable, drenaje, alcantarillado, tratamiento y disposición de aguas residuales; $b$ ) alumbrado público; c) limpia, recolección, traslado,

1 Reynoso, Diego, La estrategia dominante. Alianzas electorales en los estados mexicanos 1988-2011, Buenos Aires, Teseo-Flacso Argentina, 2011.

2 Publicada en el Diario Oficial de la Federación del 14 de agosto de 2001.

${ }^{3}$ Los estudios pioneros de Carmen Cordero Avendaño sobre usos y costumbres en Oaxaca se refieren al derecho consuetudinario en general sin énfasis en lo electoral.

4 Publicados por IDEA Internacional, el Tribunal Electoral del Poder Judicial de la Federación y el Instituto Federal Electoral en 2000 y 2006, respectivamente.

5 Dato del Instituto Nacional de Estadística y Geografía. 
tratamiento y disposición final de residuos; $d$ ) mercados y centrales de abasto; $e$ ) panteones; $f$ ) rastro; $g$ ) calles, parques y jardines y su equipamiento; $h$ ) seguridad pública, en los términos del artículo 21 de la Constitución, policía preventiva municipal y tránsito, e $i$ ) los demás que las legislaturas locales determinen según las condiciones territoriales y socioeconómicas de los municipios, así como su capacidad administrativa y financiera. Más adelante constataremos la evolución de estas atribuciones municipales a lo largo de la historia constitucional.

Según la Agenda desde lo Local. "Descentralización Estratégica para el Desarrollo de lo Local", ${ }^{6}$ basada en la Agenda Local 21 de la Organización de las Naciones Unidas, se deben tener en cuenta 39 indicadores y 257 parámetros de medición para identificar las condiciones que no deben dejar de existir en cualquier municipio y que son agrupadas según esta metodología en los cuatro siguientes rubros o cuadrantes: 1) desarrollo institucional para un buen gobierno; 2) desarrollo económico sostenible; 3) desarrollo social incluyente, y 4) desarrollo ambiental sustentable.

Se trata de una metodología o programa para el desarrollo integral de los municipios mexicanos al cual me refiero igualmente que antes a los servicios públicos municipales, para mostrar de manera amplia la complejidad e importancia de la administración municipal, y establecer de entrada la vinculación entre democracia representativa o electoral y gestión municipal. Es decir, que los sistemas electorales no pueden ser analizados en abstracto sino necesariamente en su contexto obligado. Porque los sistemas electorales y su regulación jurídica no son fines en sí mismos que se agotan con la última resolución jurisdiccional contenciosa que cierra el proceso electoral —el juicio de revisión constitucional electoral—, ${ }^{7}$ sino que establecen una continuidad institucional que influye de manera importante en la vida diaria de los electores, contribuyentes, usuarios de los servicios públicos municipales y beneficiarios de una gestión debidamente controlada gracias al poder del voto popular.

Sin embargo, por el momento este enfoque pretendidamente integral y sistémico solo puede llegar hasta aquí pues es necesario detenerse ahora en los aspectos político electorales que nos llevan a privilegiar el contexto teórico político, democrático y de gobierno, incluso en el derecho com-

6 Secretaría de Gobernación, Instituto Nacional para el Federalismo y el Desarrollo Municipal, 2004; 3a. ed., 2007.

Artículo 99, fracción IV, de la Constitución Política de los Estados Unidos Mexicanos, y Libro Cuarto, artículos 86 a 93, de la Ley General del Sistema de Medios de Impugnación en Materia Electoral. 
parado, para analizar en sus diversos aspectos la reelección inmediata en el orden municipal de gobierno que reaparece en el sistema político mexicano, en mi opinión, para beneficio de la democracia representativa y de la buena gestión de los servicios públicos municipales.

\section{Las teorías políticas}

La reelección de autoridades puede ser analizada desde la teoría de la democracia, esto es, como una expresión de la voluntad popular; desde la teoría de la representación política, como una forma de mandar y ejercer un mandato; desde la teoría de las formas de gobierno, ${ }^{8}$ como una forma de integración de élites dirigentes, o bien, desde la teoría del control del poder por el poder mismo. Sin duda puede haber otros enfoques, por ejemplo, administrativo, presupuestal, de servicio profesional, etcétera. ${ }^{9}$

La representación política, a nivel nacional, entrañó una forma de enfrentar y someter el absolutismo real, a partir de la cual se construyeron las diversas formas de constitucionalismo liberal y democrático. Por el carácter siempre ligado a la satisfacción de las necesidades más inmediatas de la población a partir de los servicios públicos municipales, la representación política municipal tiene o debería tener como un factor adicional de evaluación necesario la eficacia y eficiencia en la gestión. Es conveniente, al efecto, a la luz de la reelección municipal inmediata, reflexionar sobre la manera de integrar dicho factor de evaluación al sistema y procedimiento electoral municipal.

Es por ello que también privilegiamos las formas de control: el voto popular como el otorgamiento de un mandato amplio frente al cual la primera forma de control que tiene el elector es la sanción consistente en no volver a otorgar su voto si su representante vuelve a pedírselo, forma elemental de rendición y control de cuentas. Las muchas formas de control (político, jurisdiccional, internacional incluso) provienen o desembocan en una visión instrumental de la democracia entendida como reglas de procedimiento para hacer cada vez más efectivo el control del ciudadano-elector-contribuyente-administrado sobre sus representantes.

${ }^{8}$ Cfr. Castellanos Hernández, Eduardo de Jesús, Para entender la democracia. Teoría Política, formas de gobierno, sistemas electorales, sistemas de partidos y calidad de la democracia, México, edición del autor, 2008.

9 Se sugiere consultar: Moreno Espinosa, Roberto (coord.), Gobierno, gestión y profesionalización en el ámbito local ante los grandes retos de nuestro tiempo, así como: Arias de la Mora, Roberto, Democracia y gestión pública municipal, México, UAEM, 2011. 


\section{El sistema político}

El sistema político está formado por el sistema electoral, el sistema de partidos y el sistema o forma de gobierno. ${ }^{10} \mathrm{El}$ sistema electoral parte de dos principios básicos para la conversión de votos en cargos públicos - sistema electoral en sentido estricto-: el principio de mayoría y el principio de representación proporcional, de cuyas combinaciones más sus agregados - desde el derecho de voto hasta la solución de controversias: sistema electoral en sentido amplio- surgen las reformas electorales, algunas de fondo y otras no tanto. De las tres más recientes que hemos conocido en México —2007, 2012 y 2014, a la de 1996 ya me referiré en seguida-, la más importante sin duda es la que ahora comentamos. Como habremos de constatar más adelante, los principios y procedimientos electorales han sido comunes a las elecciones para integrar los diferentes órdenes de gobierno: federal, estatal y municipal.

El sistema de partidos puede ser clasificado por el número de éstos o por la forma de interrelación entre ellos: de partido único, bipartidismo y pluralismo, pudiendo ser éste moderado, polarizado y atomización, o bien, partido hegemónico o partido dominante, gobernante u opositor. En 1929, en México, pasamos de la atomización al régimen de partido único, para transitar lentamente del militarismo al autoritarismo moderado (aunque a veces no tanto) del partido hegemónico con elecciones testimoniales, de ahí al pluralismo virtual y finalmente al pluralismo moderado actual que más bien es un tripartidismo con un partido dominante.

El sistema de gobierno puede ser parlamentario, presidencial o semipresidencial; modelos constitucionales de los cuales en las leyes fundamentales nuestras hemos conocido todos: en 1814, parlamentarismo con Ejecutivo colegiado alternando por cuatrimestres la presidencia; en 1824 y 1857, presidencialismo con elección indirecta del Ejecutivo en tercer grado, con la intervención de las legislaturas de los estados; en 1917, hiperpresidencialismo que se agrandaría gracias a las facultades metaconstitucionales definidas por Jorge Carpizo; ${ }^{11}$ en 1993, semipresidencialismo, así fuese para la designación del entonces denominado jefe del Distrito Federal, pero del que rápidamente se regresó al modelo presidencial con la elección directa del ahora jefe de gobierno del Distrito Federal.

10 Nohlen, Dieter, Sistemas electorales en su contexto, México, UNAM-SCJN-BUAP, 2008, p. 91.

11 El presidencialismo mexicano, 4a. ed., México, Siglo XXI editores, 1984, pp. 190 y ss. 
Desde luego que la forma de gobierno también puede referirse a la monarquía y a la república, de las que también hemos conocido ambas, así como al régimen federal actual y original de 1824, restaurado en 1847 y reiterado en 1857, o la organización unitaria de las Constituciones de 1836 y 1843 . Modalidades todas que hemos conocido en determinados momentos de nuestra historia nacional, con sus respectivos municipios.

El presidencialismo latinoamericano es un caso que ha sido analizado de manera especial por otros autores como Dieter Nohlen, quien formula al efecto la siguiente tipología: presidencialismo autoritario, reforzado, puro, atenuado y parlamentarizado. ${ }^{12}$ En una publicación posterior ${ }^{13}$ Nohlen modifica su clasificación anterior de la manera siguiente: hiperpresidencialismo o dominante, reforzado o racionalizado, puro o equilibrado, atenuado y parlamentarizado. Igualmente, en el presidencialismo mexicano, el sistema político electoral municipal ha seguido los vaivenes de la transición mexicana en su larga marcha a la democracia. Reitero, los estudios que vinculen forma de gobierno nacional, sistemas electorales nacionales y subnacionales, con gobierno, administración y elecciones municipales, como objeto específico de análisis, seguramente son escasos.

En todas estas modalidades constitucionales mencionadas ha permanecido el municipio libre como forma básica de gobierno, no obstante que la mención constitucional expresa haya aparecido apenas hasta el 26 de diciembre de 1914, en una reforma a la Constitución de 1857 decretada por el primer jefe del Ejército Constitucionalista, encargado del Poder Ejecutivo de la República y jefe de la Revolución, Venustiano Carranza, en virtud de las facultades de que se encontraba investido.

\section{La reelección inmediata}

La reelección inmediata de legisladores y munícipes puede ser analizada desde la perspectiva político democrática a la que ya me he referido así como desde la de la teoría administrativa. En el caso de las teorías políticas, la libertad del elector al ejercer su voto no debe ser coartada o limitada con la prohibición de la reelección; tiene además la ventaja de permitir al representante reelecto ganar experiencia en el quehacer correspondiente y en el intercambio con sus interlocutores institucionales

12 Cfr. Nohlen, Dieter, op. cit., p. 98.

13 Nohlen, Dieter, Ciencia política comparada. El enfoque histórico-empírico, Bogotá, BUAP-Universidad del Rosario, 2013, pp. 136 y 137. 
habituales. Las desventajas podrían ser, en primer lugar, la petrificación de las élites políticas y burocráticas con la consecuente falta de circulación y renovación de las mismas, así como la creación de intereses que faciliten opacidad, corrupción y falta de rendición de cuentas.

En el caso de la teoría administrativa, ${ }^{14}$ en el enfoque de planificación y prospectiva para la construcción de escenarios de futuro para el futuro resulta indispensable incorporar los conceptos de mediano y largo plazo. No se construye y actualiza - para construir futuro- una legislación nacional o local, ni una reglamentación municipal, en un periodo de tres años; menos aún es posible consolidar obras públicas municipales, particularmente de infraestructura urbana y su equipamiento, en un periodo de tres años, ni de seis, evidentemente se requiere más tiempo para la implementación, evaluación y retroalimentación, por cuanto se refiere a la presencia de los actores individuales. Cierto es que se trata de procesos de largo plazo en los que intervienen numerosos actores, individuales y sociales, pero en los que no podemos olvidar el factor personal, individual, y su permanencia en el tiempo.

Es cierto, también, como ya apunté, que la falta de rendición de cuentas y la corrupción política y administrativa son tentaciones permanentes para las personas que ejercen cargos públicos durante periodos breves o prolongados - cuando no existe una cultura democrática consolidada en el individuo y en la sociedad-; más aún cuando los diversos controles del poder por el poder no funcionan, están mal diseñados o el autoritarismo del sistema político les impide actuar aunque existan formalmente. Entonces, frente a estas amenazas, lo que se debe hacer es eficientar los controles y no eliminar ni limitar uno de ellos, el que nos ocupa, la reelección.

Sucede que en nuestro país, después de dos prolongados mandatos presidenciales, quedó en la tradición y cultura política la satanización de la reelección inmediata sin límite de tiempo en los cargos ejecutivos (presidente, gobernadores y presidentes municipales); la no reelección fue un elemento clave del discurso legitimador de los gobiernos surgidos del partido político que se reclama o reclamó durante setenta años heredero o vocero de la Revolución mexicana. Pero la no reelección también sirvió para consolidar y mantener un régimen político que Daniel Cosío Villegas calificó como una "monarquía sexenal hereditaria en grado transversal".

La eficacia del discurso no reeleccionista permitió que no obstante que "las percepciones de los mexicanos sobre el sistema político han sufrido

14 Cfr. Sfez, Lucien, L’administration prospective, París, Librairie Armand Colin, 1970. 
transformaciones importantes en la última década... en el imaginario social mexicano, la reelección se vincula a un régimen dictatorial y no con la democracia". ${ }^{15}$ Lo paradójico, además, es que los dos presidentes que duraron mayor número de años en el cargo, son los que pudieron acreditar el mayor número de realizaciones políticas, en un caso, y materiales, en el otro: Benito Juárez y Porfirio Díaz.

También es cierto que en el presidencialismo latinoamericano, ya en su etapa de democratización e incluso en su versión socializante -llamadas democracias populares o con otros adjetivos-, la tendencia a la reelección inmediata sin límite de tiempo ha sido una tentación para los liderazgos mesiánicos autoritarios, como ha sido el caso de Fidel Castro Ruz, Hugo Chávez Frías y otros más. Cabe recordar que la dictadura cubana tiene una forma de gobierno parlamentaria y que la dictadura militar de Augusto Pinochet sometió su permanencia a un referéndum. En un caso nos permite recordar a autores europeos que han propuesto al parlamentarismo como una forma de democratizar la región latinoamericana y en el otro las vías institucionales de la transición a la democracia.

\section{La reelección municipal inmediata en Latinoamérica}

Como veremos más adelante, en los documentos del proceso legislativo de la reforma en comento se señala que respecto de la reelección inmediata, en América Latina, solo México y Costa Rica la impiden actualmente, pero no hace la distinción entre la reelección inmediata de ejecutivos, legisladores y autoridades municipales. A reserva de un estudio exhaustivo respecto del tema, adelanto una muestra aleatoria de varios casos nacionales en la región.

Argentina es una república federal cuya Constitución nacional remite la regulación del régimen municipal a las Constituciones provinciales. En el caso de la provincia de Tucumán, por ejemplo, la administración municipal es ejercida por un Departamento Ejecutivo y un Concejo Deliberante. El Departamento Ejecutivo está a cargo de un intendente electo de forma directa por mayoría relativa, en caso de empate decide el Concejo Deliberante; si hubiese tres elecciones con empate se realiza un sorteo supervisado por la Corte Suprema de la provincia. El intendente dura

15 Flores, Julia Isabel et al., "Reelección y democracia: cambios en los valores de la población”, Revista Mexicana de Derecho Electoral, núm. 2, p. 469. 
cuatro años en su cargo y su reelección tiene las mismas limitaciones que para el gobernador de la provincia, es decir, puede haber una reelección consecutiva y para volver a ocupar el cargo debe transcurrir un periodo; esta regla es la misma para la elección de vicegobernador, el cual después de dos periodos como tal puede ser gobernador y ser reelecto. El Concejo Deliberante está compuesto por el número de integrantes que señale la ley conforme a la categoría del municipio; duran cuatro años y pueden ser reelectos de la misma forma que los legisladores provinciales, es decir, pueden ser reelectos por un periodo consecutivo pero para volver a postularse debe transcurrir un periodo de intervalo.

En Venezuela, la Ley Orgánica del Poder Público Municipal, del 28 de diciembre de 2010, promulgada y publicada por el presidente Hugo Chávez Frías, establece que dicho poder se ejerce a través de cuatro funciones: la ejecutiva (alcalde o alcaldesa), la deliberativa (Concejo Municipal), la de control fiscal (Contraloría Municipal) y la de planificación (ejercida corresponsablemente con el Consejo Local de Planificación Pública). El alcalde o alcaldesa, así como los integrantes del Concejo Municipal provienen de una elección directa, duran cuatro años y no se regula la posibilidad de reelección. En la Ley Orgánica del Régimen Municipal de 1989, durante el gobierno de Carlos Andrés Pérez, el alcalde o alcaldesa podía ser reelecto para el periodo siguiente pero para volver a postularse deberían haber transcurrido dos periodos.

La Constitución Política de Colombia prevé la reelección consecutiva para el presidente y el vicepresidente, cuyo periodo en el cargo es de cuatro años pudiendo ser reelectos. En el caso de los gobernadores y alcaldes el periodo en el cargo es también por cuatro años pero sin opción a ser reelectos de manera consecutiva, sin mayor especificación.

Por su parte, la Constitución Política de Guatemala establece que el gobierno municipal será ejercido por un concejo el cual se integra con el alcalde, los síndicos y concejales, los cuales son electos directamente mediante sufragio universal y secreto para un periodo de cuatro años, pudiendo ser reelectos. La ley suprema de Guatemala no especifica o limita las veces que pueda ocurrir la reelección.

En tanto que la Constitución Política de Nicaragua establece como autoridades municipales al alcalde, el vicealcalde y los concejales quienes son elegidos por el pueblo mediante el sufragio universal, igual, directo, libre y secreto. El alcalde y vicealcalde son elegidos mediante la mayoría relativa de los votos, en tanto que los concejales son electos por representación proporcional mediante cociente electoral. El alcalde y el vicealcalde solo podrán ser reelectos por un periodo pero no para el inmediato siguiente. 


\section{La historia constitucional nacional}

Como sabemos somos herederos de tres tradiciones constitucionales: la española derivada de la Constitución de Cádiz, la francesa de los derechos del hombre y la estadounidense proveniente de su única Constitución, incluidas en ésta sus enmiendas y criterios jurisprudenciales. Por razón natural, en el transcurso del tiempo otras influencias constitucionales, pero también de tratados internacionales - desde hace pocos años, los tratados en materia de derechos humanos los más, incluidas las sentencias y jurisprudencia vinculantes para México de tribunales internacionales-, han sido estudiadas, adoptadas y adaptadas por nuestros legisladores y tribunales constitucionales.

\section{El sistema electoral de Cádiz}

Desde Cádiz hasta la Constitución nuestra de 1857, las elecciones fueron indirectas en cuarto, tercero y primer grado, sucesivamente; hubo entonces elecciones de compromisarios, electores de parroquia, de partido y de provincia, para elegir éstos a los representantes ante las Cortes. Es a partir de la Ley Electoral de 1911, según las reformas del 22 de mayo de 1912, que se establece la elección directa de legisladores federales, pero será hasta el texto original de la Constitución de 1917 en que todas las elecciones serán directas.

\section{El gobierno interior de las provincias y de los pueblos}

El gobierno político de las provincias residía en el jefe superior nombrado por el rey. En cada provincia había una diputación provincial formada por siete individuos elegidos y renovados por mitad cada dos años. Su elección se llevaba a cabo por los electores de partido al día siguiente de haber nombrado a los diputados de Cortes, "por el mismo orden con que estos se nombran". Había tres suplentes por cada diputación. Los requisitos para ser diputado provincial eran los mismos que para los de Cortes, pero se agregaba que la residencia no debería ser menor de siete años " $y$ que tenga lo suficiente para mantenerse con decencia y no podrá serlo ninguno de los empleados de nombramiento del Rey". No había reelección inmediata pero sí mediata, una vez pasados cuatro años "de haber cesado en sus funciones". 
Para el gobierno interior de los pueblos había ayuntamientos compuestos de alcalde o alcaldes, regidores y el procurador síndico presididos por el jefe político donde lo hubiere o en su defecto por el alcalde, o el primero de los nombrados entre ellos si hubiese dos alcaldes.

La Constitución dispuso que sería nombrado un ayuntamiento en los pueblos donde no lo hubiese y conviniese que lo hubiera, pero sería obligatorio en los pueblos que por sí o con su comarca llegaran "a mil almas". Las leyes determinarían el número de individuos de cada clase que habrían de componer los ayuntamientos de los pueblos con respecto a su vecindario.

Los alcaldes, regidores y procuradores síndicos eran nombrados por elección en los pueblos, para lo cual cesaron los regidores y demás que servían oficios perpetuos en los ayuntamientos, independientemente de su título o denominación.

En el mes de diciembre de cada año se reunían los ciudadanos de cada pueblo, para elegir a pluralidad (mayoría) de votos, con proporción a su vecindario, determinado número de electores que residiesen en el mismo pueblo y que estuviesen en el ejercicio de sus derechos ciudadanos. Los electores nombraban en el mismo mes, a pluralidad absoluta de votos, el alcalde o alcaldes, regidores y procurador o procuradores síndicos, quienes entraban a ejercer sus cargos el primero de enero del año siguiente (elección indirecta en primer grado).

Los alcaldes cambiaban cada año, los regidores eran renovados por mitad cada año y lo mismo los procuradores síndicos donde hubiese dos, pero si hubiese solo uno cambiaba cada año.

El que hubiese ejercido cualquiera de estos cargos no podía volver a ser elegido para ninguno de ellos sin que hubiesen pasado por lo menos dos años, "donde el vecindario lo permita" (no reelección consecutiva o inmediata pero sí mediata).

Para ocupar cualquiera de los cargos mencionados era necesario ser ciudadano en el ejercicio de sus derechos, mayor de veinticinco años con cinco por lo menos de vecindad y residencia en el pueblo. Las leyes determinarían las demás calidades que habrían de tener "estos empleados". Nadie podía excusarse sin causa legal de ocupar los cargos concejiles mencionados.

Pero no podía ocupar ninguno de esos cargos ningún empleado público de nombramiento del rey que estuviese en ejercicio, no estando comprendido en este supuesto "los que sirvan en las milicias nacionales".

En todo ayuntamiento había un secretario electo por mayoría absoluta de votos, "y dotado de los fondos del común". 
Estaba a cargo de los ayuntamientos:

Primero. La policía de salubridad y comodidad.

Segundo. Auxiliar al alcalde en todo lo que pertenezca a la seguridad de las personas y bienes de los vecinos, y a la conservación del orden público.

Tercero. La administración e inversión de los caudales de propios y arbitrios conforme a las leyes y reglamentos, con el cargo de nombrar depositario bajo responsabilidad de los que le nombran

Cuarto. Hacer el repartimiento y recaudación de las contribuciones y remitirlas a la tesorería respectiva.

Quinto. Cuidar de todas las escuelas de primeras letras, y de los demás establecimientos que se paguen de los fondos del común.

Sexto. Cuidar de los hospitales, hospicios, casas de expósitos y demás establecimientos de beneficencia, bajo las reglas que se prescriban.

Séptimo. Cuidar de la construcción y reparación de los caminos, calzadas, puentes y cárceles, de los montes y plantíos del común, y de todas las obras públicas de necesidad, utilidad y ornato.

Octavo. Formar las ordenanzas municipales del pueblo, y presentarlas a las Cortes para su aprobación por medio de la diputación provincial, que las acompañará con su informe.

Noveno. Promover la agricultura, la industria y el comercio según la localidad y circunstancias de los pueblos, y cuanto les sea útil y beneficioso.

Si se ofreciesen obras $u$ otros objetos de utilidad común y no fuesen suficientes los caudales de propios y fuese necesario recurrir a arbitrios, no podían imponerse éstos, sino obteniendo por medio de la diputación provincial la aprobación de las Cortes. En casos urgentes, los ayuntamientos podían utilizar interinamente de ellos con aprobación de la diputación provincial mientras llegase la resolución de las Cortes.

Los ayuntamientos desempeñaban todos estos encargos bajo la inspección de la diputación provincial, a la que rendían cuenta justificada cada año de los caudales públicos que hubiesen recaudado e invertido.

\section{La no reelección municipal consecutiva en México}

En realidad no siempre hubo, antes de los gobiernos surgidos de la guerra civil conocida habitualmente como Revolución mexicana, reelección inmediata de las autoridades municipales en México o una referencia ex- 
presa al respecto. Un breve estudio de los documentos fundadores de la República y de sus antecedentes constitucionales, por cuanto se refiere a elecciones y organización municipal, nos entrega los siguientes resultados: Elementos de nuestra Constitución del 30 de abril de 1812:

23. Los representantes serán nombrados cada tres años por los ayuntamientos respectivos, y éstos deberán componerse de las personas más honradas, y de proporción no solo de las capitales sino de los pueblos del distrito.

El Decreto Constitucional para la Libertad de la América Mejicana o Constitución de Apatzingán del 22 de octubre de 1814, regula la representación nacional pero no la provincial o estatal ni la municipal. El Plan de Iguala y los Tratados de Córdoba, al igual que antes los Sentimientos de la Nación, tampoco aluden a la organización provincial o estatal ni a la municipal. Sin embargo, el Reglamento Provisional Político del Imperio Mexicano, del 23 de febrero de 1823, regula en forma precisa el "Gobierno particular de las provincias y pueblos con relación al Supremo del Imperio", incluidos diputados provinciales, ayuntamientos, alcaldes, regidores y síndicos; quedando éstos sujetos a la reglamentación expedida por las diputaciones provinciales y "a la inspección del jefe político subalterno más inmediato del propio partido”, en la forma siguiente:

Art. 96. Se adaptará dicho reglamento a la situación y circunstancias de cada pueblo, a fin de conservar en todos el orden público y promover el bien, autorizando a los alcaldes para conciliar desavenencias, despachar demandas de poca entidad, evitar desórdenes de toda especie, imponer arrestos y correcciones ligeras; y obligándolos a aprehender a los delincuentes y ponerlos a disposición del jefe político de su partido, o del juez de primera instancia más inmediato a quien toque conocer de esta especie de causas, como de las civiles de más entidad que los indicados alcaldes no hayan dirimido por sí, ni terminado por conciliación.

La primera Constitución federal de 1824 no reguló la organización municipal, respecto del gobierno particular de los estados solo estableció, además de sus obligaciones y restricciones, la división de tres poderes: Legislativo, Ejecutivo y Judicial. Es en la sexta de las siete Leyes Constitucionales de 1836 donde se regula también con detalle el gobierno interior de los pueblos y se alude a la reelección municipal de la siguiente forma: "Art. 30. Los cargos de sub-prefectos, alcaldes, jueces de paz encargados de la policía, regidores y síndicos, son concejiles, no se po- 
drán renunciar sin causa legal, aprobada por el gobernador, o en caso de reelección". ${ }^{16}$

Por cuanto a las atribuciones de los ayuntamientos estableció:

Art. 25. Estará a cargo de los ayuntamientos la policía de salubridad y comodidad; cuidar de las cárceles, de los hospitales y casas de beneficencia, que no sean de fundación particular, de las escuelas de primera enseñanza que se paguen de los fondos del común, de la construcción y reparación de puentes, calzadas y caminos y de la recaudación e inversión de los propios y arbitrios; promover el adelantamiento de la agricultura, industria y comercio y auxiliar a los alcaldes en la conservación de la tranquilidad y el orden público en su vecindario, todo con absoluta sujeción a las leyes y reglamentos.

Las Bases Orgánicas de 1843, la otra Constitución centralista, es el único ordenamiento constitucional que ha dedicado un título expreso a regular el Poder Electoral, aunque en realidad solo haya reunido en un único apartado las disposiciones que los demás ordenamientos han establecido de manera dispersa; además, no instituyó una autoridad electoral expresa, central o descentralizada, como sucedió hasta 1946 con la Comisión Federal de Vigilancia Electoral, aunque ésta haya sido establecida solo en la Ley Federal Electoral, a diferencia del Instituto Federal Electoral regulado desde la Constitución hasta apenas $1990 .{ }^{17}$

El Acta de Reformas de 1847 si bien estableció expresamente la posibilidad de que pudiera "adoptarse la elección directa" en las elecciones, no se refirió a la cuestión municipal; tampoco el Plan de Ayutla ni el Estatuto Orgánico Provisional de la República, de 1854 y 1856, respectivamente. La Constitución de 1857, como ya se ha señalado, se refirió al tema hasta la reforma de 1914. En cambio, el Estatuto Provisional del Imperio Mexicano de 1865 dedicó su título IX a los prefectos políticos, subprefectos y municipalidades; de los alcaldes, el de la capital sería nombrado y removido por el emperador, los demás por los prefectos, "salvo rectificación soberana". Sin embargo también estableció que: "Artículo 43. Los Ayuntamientos formarán el Consejo de Municipio, serán elegidos popularmente en elección directa, y se renovarán por mitad cada año".

Disposición de donde se entiende que no había posibilidad de reelección inmediata, aunque la suposición no implica seguridad pues a falta de disposición expresa la aplicación está sujeta a interpretación de la norma.

16 Énfasis añadido.

17 Diario Oficial de la Federación, 6 de abril de 1990. 
El Plan de la Noria, del 9 de noviembre de 1871, con el cual el general Porfirio Díaz se opuso al presidente Benito Juárez, proclamó lo siguiente: "Que la Unión garantice a los Ayuntamientos derechos y recursos propios como elementos indispensables para su Libertad e Independencia”.

En el Plan de Tuxtepec, del 10 de enero de 1876, con el cual el general Díaz se levanta en contra del presidente Sebastián Lerdo de Tejada y triunfa, la proclama incluyó "la no reelección del Presidente de la República y Gobernadores de los Estados", así como garantizar "la independencia de los municipios".

El Programa del Partido Liberal Mexicano, del 1o. de julio de 1906, cuya realización sería "estrictamente obligatoria" a la caída de la dictadura del general Díaz - que desde luego no logró materializar el Partido Liberal, pero cuya herencia política y social fue reivindicada por los gobiernos revolucionarios posteriores-, se propuso: “46. Reorganización de los municipios que han sido suprimidos y robustecimiento del poder municipal”.

Por su parte, el Plan de San Luis, del 5 de octubre de 1910, encabezado por Francisco I. Madero en contra de Díaz, además de convocar a tomar las armas el domingo 20 de noviembre de 1910 a partir de las seis de la tarde, mantuvo el principio del Partido Nacional Antireeleccionista que lo había postulado en las elecciones de ese año en las que contendió y perdió frente a Díaz: Sufragio Efectivo y No Reelección, en los términos siguientes:

$4^{\circ}$ Además de la Constitución y leyes vigentes, se declara ley suprema de la República el principio de No Reelección del Presidente y Vice-presidente de la República, de los Gobernadores de los Estados y presidente Municipales, mientras se hagan las reformas constitucionales respectivas.

El Plan de Ayala, del 28 de noviembre de 1911, reformado el 30 de mayo de 1913 — de Emiliano Zapata en contra de Madero y después en contra de Victoriano Huerta, quien había ordenado el asesinato de Madero y usurpado el poder presidencial-, así como el Plan de Guadalupe, del 26 de marzo de 1913 y sus adiciones del 12 de diciembre de 1914 — de Venustiano Carranza en contra de Victoriano Huerta-, no se refirieron a la cuestión municipal. Las modificaciones al Plan de Guadalupe del 14 de septiembre de 1916, incluyeron el compromiso de instalar un congreso constituyente, del cual surgió la Constitución actual promulgada el 5 de febrero de 1917.

Me he referido ya al decreto del 26 de diciembre de 1914 del primer jefe de la Revolución, en esa etapa, Venustiano Carranza - autor de la 
legislación preconstitucional, de la cual-por razones que no abordamos aquí - hasta la fecha permanece en vigor la Ley de Delitos de Imprenta-, por virtud del cual el artículo 109 de la Constitución de 1857 quedó como sigue:

Los Estados adoptarán para su régimen interior la forma de gobierno republicano representativo, popular, teniendo como base de su división territorial y de su organización política, el Municipio Libre, administrado por Ayuntamiento de elección popular directa y sin que haya autoridades intermedias entre estos y el gobierno del Estado.

El Ejecutivo Federal y los gobernadores de los estados tendrán el mando de la fuerza pública de los municipios donde residieren habitual o transitoriamente.

Los Gobernadores no podrán ser reelectos ni durar en su encargo por un periodo mayor de seis años.

La prohibición no incluye a las autoridades municipales. El municipio libre fue regulado en el artículo 115 de la Constitución de 1917 a partir de los mismos principios, a los que se agregó la libre administración de la Hacienda pública municipal, formada con las contribuciones señaladas por las Legislaturas de los Estados, teóricamente suficientes para atender sus necesidades, así como la personalidad jurídica de los municipios. La prohibición de la reelección de los gobernadores constitucionales se mantuvo, sin hacerla extensiva a las autoridades municipales; tampoco hubo prohibición para que los miembros del Poder Legislativo pudiesen ser reelectos. Por su parte, el artículo 83 del nuevo texto constitucional mantuvo la no reelección del presidente constitucional y del interino, previamente establecida para el presidente y el vicepresidente mediante una reforma al artículo 78 de la Constitución de 1857, del 28 de noviembre de 1911, promulgada y publicada por el presidente Madero.

El artículo 83 fue reformado en $1927^{18}$ para permitir la reelección presidencial por una sola vez transcurrido el periodo inmediato siguiente; terminado el desempeño del segundo periodo ya no se podría volver a ejercer el cargo. El presidente reelecto Álvaro Obregón fue asesinado antes de tomar posesión.

En 1933 el mismo artículo fue reformado ${ }^{19}$ para establecer que por ningún motivo, quien hubiese desempeñado el cargo de presidente, sin

18 Diario Oficial de la Federación, 22 de enero de 1927.

19 Diario Oficial de la Federación, 29 de abril de 1933. 
importar el carácter de electo, interino, provisional o sustituto, podrá volver a ejercerlo. Por cuanto a los diputados, senadores y funcionarios municipales, en la misma reforma se estableció la prohibición de su reelección inmediata. Una nueva reforma, en $1953,{ }^{20}$ precisa la no reelección inmediata de los presidentes municipales, regidores y síndicos de los ayuntamientos.

Para efecto de contexto es importante recordar que en 1947 se estableció el derecho de voto activo y pasivo de las mujeres en las elecciones municipales, ${ }^{21}$ el cual fue ampliado en 1953 a todo tipo de elección. ${ }^{22}$ En 1977 se introduce el principio de representación proporcional en la elección de ayuntamientos en los municipios cuya población fuese de 300000 o más habitantes; ${ }^{23}$ el cual fue ampliado en $1983^{24}$ para todos los ayuntamientos. En 2001 se establece que en los municipios con población indígena se podrán elegir autoridades municipales de conformidad con sus tradiciones y normas internas (usos y costumbres). ${ }^{25}$

\section{El Pacto por México}

El antecedente de acuerdo político más cercano en la magnitud de sus resultados al que se logró bajo la denominación Pacto por México, ${ }^{26}$ fue el Acuerdo Político Nacional del 17 de enero de 1995, mismo que dio origen a la reforma constitucional en materia político electoral publicada en el Diario Oficial de la Federación del 22 de noviembre de 1996, cuya iniciativa fue suscrita conjuntamente por el presidente de la República y los coordinadores de los grupos parlamentarios de ambas cámaras del Congreso de la Unión. ${ }^{27}$

Sin embargo, el Pacto por México — suscrito por los dirigentes nacionales de los tres partidos políticos con mayor votación en las elecciones presidenciales de 2012: PRI, PRD y PAN - tuvo una amplitud y conse-

\footnotetext{
20 Ibidem, 17 de octubre de 1953.

21 Ibidem, 12 de febrero de 1947.

22 Ibidem, 17 de octubre de 1953.

23 Ibidem, 6 de diciembre de 1977.

24 Ibidem, 3 de febrero de 1983.

25 Ibidem, 14 de agosto de 2001.

26 Ibidem, 2 de diciembre de 2012.

27 Cfr. Castellanos Hernández, Eduardo, Las reformas de 1996, México, Centro de Investigación Científica "Ing. Jorge L. Tamayo", 1998, p. 12.
} 
cuencias inmediatas mayores pues, de una parte, abarcó los siguientes grandes temas o acuerdos, a los cuales correspondieron un total de 95 compromisos de acción específica: 1) sociedad de derechos y libertades; 2) crecimiento económico, empleo y competitividad; 3) seguridad y justicia; 4) transparencia, rendición de cuentas y combate a la corrupción, y 5) gobernabilidad democrática.

Los Acuerdos para la Gobernabilidad Democrática implicaron lo siguiente: 5.1 ) gobiernos de coalición (compromiso 87); 5.2) toma de protesta del presidente el 15 de septiembre (compromiso 88); 5.3) partidos políticos y elecciones (compromisos 89 y 90); 5.4) reforma del distrito federal (compromiso 91); 5.5.) revisión global de los fueros (compromiso 92); 5.6) leyes reglamentarias de la reforma política (compromiso 93); 5.7) revisar la reelección de legisladores (compromiso 94);28 5.8) medios de comunicación (compromiso 95).

Como puede apreciarse, en dichos acuerdos no estuvo incluida la reelección inmediata de las autoridades municipales, la cual surge en el proceso legislativo posterior que materializa el compromiso político correspondiente a la reelección legislativa.

\section{El proceso legislativo de la reforma de 2014}

La iniciativa de reforma constitucional en materia político electoral presentada por los senadores de los grupos parlamentarios de los partidos Acción Nacional y de la Revolución Democrática el 24 de julio de 2013, argumenta respecto de la reelección municipal en forma conjunta con lo relativo a la reelección legislativa de la siguiente manera:

Finalmente, en el ámbito de la rendición de cuentas, se requieren modificaciones constitucionales para dos temas:... reelección legislativa y de autoridades municipales... Por último, eliminar la prohibición a la reelección legislativa es probablemente la reforma más importante para profesionalizar la actividad legislativa, otorgar poder de decisión al ciudadano sobre la carrera política de sus gobernantes y dar sustancia representativa a nuestra democracia.

28 Énfasis añadido. 


\section{Reelección}

Finalmente, uno de los temas más discutidos en todos los procesos de reforma política en nuestra historia es la posibilidad de terminar con la prohibición constitucional para la reelección legislativa y de autoridades municipales.

México es uno de los pocos países democráticos que no permite la reelección de legisladores. En el Continente Americano, sólo Costa Rica lo acompaña en esa excentricidad. La reelección inmediata de legisladores y de otros cargos públicos en el ámbito local constituye un círculo virtuoso de cercanía entre representantes y representados, que favorece al escrutinio ciudadano al promover la rendición de cuentas y una mayor profesionalización de los funcionarios.

Nuestras constituciones de 1824, 1857 e inclusive la de 1917 no prohibían la reelección inmediata de los legisladores. No es, pues, parte inherente a nuestra historia, como argumentan algunos de sus escasos opositores.

Fue apenas en 1933 que la prohibición se incorporó a la Constitución y, con ello, se privilegió el fortalecimiento gradual del Poder Ejecutivo a expensas del Poder Legislativo. Alonso Lujambio Irazábal fue uno de sus defensores más férreos. Afirmaba que: "una democracia no es virtuosa cuando desperdicia el talento de sus políticos", "que quienes hagan su trabajo correctamente, sean premiados con el voto ciudadano. Y que quienes le fallen a sus representados, sean castigados también a través del voto".

Se han presentado un sin fin de iniciativas en el Congreso para terminar con esta restricción a la democracia y la rendición de cuentas. Hace algunos años, el 10 de febrero de 2005, en la LIX Legislatura, las Comisiones Unidas de Puntos Constitucionales y de Estudios Legislativos, Segunda presentaron un dictamen al pleno del Senado de la República en donde señalaban las ventajas de la reelección inmediata y los beneficios para los ciudadanos: 1) evitar el alejamiento de los legisladores de sus representados y 2) una mayor especialización y profesionalización del trabajo legislativo. Seguir negando la posibilidad a los ciudadanos de determinar con su voto el futuro político de sus representantes es inaceptable.

El poder que la reelección da a los ciudadanos sobre sus representantes es probablemente el argumento más sólido a favor y, curiosamente, en contra de la iniciativa. Quienes abogan a favor de la reelección sostienen que esto volverá más visible el trabajo de los legisladores ante los ciudadanos. El incentivo de mantener un encargo hará que los legisladores sean más responsivos a las demandas de su electorado y más transparentes en sus gestiones.

Por otro lado, el poder de negociación que adquieren los electores de esta manera, incrementa el interés por vigilar a sus representantes. 
Quienes se oponen a la reelección, argumentan que la atención a las demandas ciudadanas pudiera repercutir en el debilitamiento de la cohesión y disciplina partidaria implicando tácitamente que los intereses partidarios no estarán alineados a los ciudadanos. Este argumento ignora que, de cumplirse su previsión, las responsabilidades individuales de los legisladores se vuelven más identificables. ¿Cuáles serían las razones de un legislador para votar en sentido contrario al de su bancada?, ¿tendría que transparentarlas?, ¿tendría que hacerlo su bancada? De ser acertado en su predicción, entonces, la reelección permitiría construir mayorías que trasciendan a los partidos políticos, mayorías coyunturales y dinámicas, que devuelvan la identidad a los legisladores individuales y los obliguen a posicionarse públicamente en torno a sus decisiones.

Quienes se oponen a la reelección también argumentan que ésta genera anquilosamiento en las legislaturas porque un legislador que ocupe un cargo será reelecto con una probabilidad muy alta. Esta idea es impulsada por las tasas de reelección que se ven en países como Estados Unidos, por ejemplo. En este sentido vale la pena considerar dos cosas. Primero, que en nuestro sistema, muchos legisladores tienen experiencia legislativa previa. Ya sea que transiten de la Cámara de Diputados a la de Senadores (o al revés) o que participen intermitentemente de las legislaturas locales y federal. Es decir, el sistema actual no garantiza una "renovación" de cuadros políticos. El problema de la perpetuación en las legislaturas como se da hoy en día, es que no guarda relación alguna con el desempeño desde la perspectiva ciudadana, lo que debería de ser el parámetro principal. De todos modos, considerando esto, esta iniciativa propone un plazo definido para la reelección. Concretamente, propone eliminar la restricción constitucional a que los legisladores puedan reelegirse en periodos consecutivos de tal manera que un legislador, federal o local, no importando si se trata del titular o del suplente, sólo pueda ocupar su cargo de manera continua hasta por un periodo de doce años, debiendo esperar al menos un periodo para estar en posición de volver a ocupar el mismo cargo. Con esto se busca equilibrar los beneficios de la reelección con los de la rotación y renovación en los cargos legislativos.

En segundo lugar, es pertinente argumentar que la experiencia legislativa disminuye los costos de aprendizaje, facilita la toma de decisiones y genera especialización en temas o regiones al interior del Poder Legislativo. Si la permanencia en el encargo es producto de un buen desempeño, su profundización no puede ser interpretada como perniciosa para la labor democrática. Ni la Legislatura, ni el municipio, deben servir para dar trabajo al menos experimentado, sino al mejor. Y ese indicador de calidad debe provenir del correcto ejercicio de sus responsabilidades de representación. 
Es importante entender que la reelección no es una garantía de permanencia. Es decir, el hecho de que los legisladores y las autoridades municipales puedan aspirar a ser reelectos no garantiza que vayan a serlo. En este sentido, podríamos esperar que los órganos de representación se vayan decantando conforme los electores van castigando a los representantes con mal desempeño.

Con estas medidas, la participación democrática de la ciudadanía se amplía. Hoy nuestra legislación ya contempla las candidaturas independientes. Esto implica abrir el espectro de participación ciudadana en la agenda pública. La reelección actúa en el mismo sentido, pero es un mecanismo con costos significativamente menores de participación. Todo ciudadano tiene poder de incidir sin tener que ser candidato por sí mismo; todos los ciudadanos tienen el incentivo para ejercitar su ciudadanía cuando su voz cuenta y sus elecciones repercuten. Es decir, la reelección fortalece la esencia de la democracia representativa y con ello, mejora necesariamente su funcionamiento.

En relación a las legislaturas locales, esta iniciativa únicamente remueve la prohibición de la reelección, dejando a los Congresos locales la decisión de adoptar o no el modelo. En lo que corresponde a las autoridades municipales, esta iniciativa plantea que los presidentes municipales, regidores y síndicos de los ayuntamientos puedan ser electos hasta por un máximo de doce años consecutivos en periodos cuya duración sea establecida por las Constituciones de los estados, y que en ningún caso exceda los cuatro años. ${ }^{29}$

Adicionalmente a las ventajas que tiene la reelección legislativa, cabe resaltar que en el caso de las autoridades municipales, a éstas hay que sumar la posibilidad de que reelegirse amplía los horizontes de planeación y, con ello, incentiva proyectos de mayor envergadura. Por sus funciones, las autoridades municipales deberían ser las que tuvieran una relación más directa con su electorado. Permitir su reelección no sólo fomenta una relación de mayor transparencia y rendición de cuentas o una mayor participación del electorado, sino que puede tener efectos positivos sobre el capital social de los municipios. ${ }^{30}$

Con fecha 2 de diciembre de 2013, el Pleno de la Cámara de Senadores dio primera lectura al dictamen con el proyecto de decreto de la reforma que se analiza. Dicho dictamen de las Comisiones Unidas de Puntos Constitucionales, de Gobernación, de Reforma del Estado, de Estudios Legislativos, Primera, y de Estudios Legislativos, Segunda, en relación

29 Énfasis añadido.

30 Sistema de Información Legislativa de la Secretaría de Gobernación, http://sil.go bernacion.gob.mx/Archivos/Documentos/2013/07/asun_2992011_20130724_137467724 3.pdf. 
con 36 iniciativas de reforma constitucional en la misma materia político electoral argumentó lo siguiente respecto al tema que nos ocupa:

\section{REELECCIÓN CONSECUTIVA DE AYUNTAMIENTOS}

En lo que respecta a la reelección consecutiva de ayuntamientos, estas comisiones unidas elaboramos un análisis de carácter histórico-doctrinal con el propósito de concluir en la procedencia o no de las propuestas.

En México, el Ayuntamiento data de la época de la conquista española. Constituye el órgano colegiado que conforma la autoridad política y representa a la organización política-administrativa que se denomina Municipio Libre.

El Ayuntamiento, de conformidad con el artículo 115 de la Constitución Política de los Estados Unidos Mexicanos, es designado por voto universal, directo y secreto, prohibiéndose su reelección inmediata.

A partir del año 1983, se han introducido diversas innovaciones a las atribuciones del Ayuntamiento, destacando "el principio de la representación proporcional", cuyo objeto dio cabida a las minorías representativas y, con ello, impulsó la incorporación de la pluralidad a la integración de estos órganos de gobierno.

Ante la evolución pluralista de la vida política-social de la Nación, se ha reconocido la necesidad de continuar ampliando los cauces de participación de la sociedad desde la base de la pirámide socio-política que es el Municipio. Sin embargo, más que un problema político, la vida municipal enfrenta serios problemas estructurales y multifactoriales, que no permiten en la práctica llegar al concepto constitucional del "Municipio Libre". La capacidad de captación fiscal es prácticamente nula y la planeación estratégica de su desarrollo en distintos ámbitos, es por demás limitada.

En ese orden de ideas, estas Comisiones Unidas, estimamos procedente reformar el artículo 115 de la Constitución a efecto de que los estados, en ejercicio de su autonomía, determinen en sus Constituciones la elección consecutiva de los miembros de los Ayuntamientos hasta por un periodo adicional. ${ }^{31}$

En su caso, los integrantes de los Ayuntamientos que hayan sido postulados por un partido político o por una coalición de partidos, requerirán que la postulación para su reelección se realice por el mismo partido o alguno de los partidos de la coalición, sin que pueda hacerse por la vía de la candidatura independiente.

Los que hayan sido electos por la vía de la candidatura independiente, solo podrán ser reelectos con ese mismo carácter, sin que puedan ser postulados por candidato político o coalición alguna.

31 Énfasis añadido. 
En el régimen transitorio, estas Comisiones proponen que la reelección de Ayuntamientos sea aplicable en los estados que opten por dicho régimen, para los integrantes de los ayuntamientos que sean electos a partir del segundo periodo inmediato posterior a aquél en que se realicen las modificaciones constitucionales para la implementación de la reelección. ${ }^{32}$

El 3 de diciembre de 2013, el pleno de la Cámara de Senadores, aprobó por 107 votos en pro, 16 en contra y 1 abstención, el dictamen relativo, enviando al siguiente día la minuta correspondiente a la Cámara de Diputados para sus efectos constitucionales.

El 5 de diciembre de 2013, en sesión de la Cámara de Diputados, fue aprobado por 409 votos en pro, 69 en contra y 3 abstenciones, el dictamen de la minuta recibida, por lo que el expediente fue turnado el mismo día a la Cámara de Senadores para los efectos del inciso E del artículo 72 constitucional.

El 6 de diciembre de 2013, el presidente de la mesa directiva del Senado, con fundamento en lo dispuesto en el artículo 176 del Reglamento del Senado, dispuso el turno directo de la minuta referida en el punto anterior a las comisiones dictaminadoras, a fin de que procedieran al análisis de la misma y formular el dictamen procedente. El 13 de diciembre de 2013, la Cámara de Senadores elaboró análisis comparativo y dictamen respecto de la minuta de referencia. El propio 13 de diciembre de 2013, la Cámara de Senadores aprobó las modificaciones señaladas por la Cámara de Diputados, remitiendo la Minuta con Proyecto de Decreto a las legislaturas locales.

El 21 de enero de 2014, la Cámara de Senadores integró el expediente para formular la declaratoria de reforma, misma que contempla 18 votos aprobatorios de los congresos de Baja California, Baja California Sur, Colima, Coahuila, Durango, Guanajuato, Jalisco, Estado de México, Morelos, Nayarit, Nuevo León, Puebla, Querétaro, San Luis Potosí, Sinaloa, Tamaulipas, Tlaxcala y Zacatecas.

El 22 de enero de 2014, la Comisión Permanente del Honorable Congreso de la Unión, a través de la Cámara de Senadores, turnó al Ejecutivo para su publicación el Decreto con la declaratoria de reforma constitucional, el cual fue publicado el 10 de febrero de 2014 en el Diario Oficial de la Federación.

32 Cámara de Senadores, www.senado.gob.mx/sgsp/gaceta/62/2/2013-12-02-1/assets/ documentos/Dic_Reforma_Politica.pdf. 


\section{La reforma de 2014}

En la parte final del libro Nuevo derecho electoral mexicano, ${ }^{33}$ realizo un análisis de la reforma constitucional que ahora nos ocupa, destacando de la misma los siguientes aspectos abordados en un total de 93 subtemas identificados: 1) planeación del desarrollo; 2) suspensión de derechos y garantías; 3) estrategia nacional de seguridad pública; 4) derechos del ciudadano; 5) partidos políticos, candidaturas, precampañas y campañas electorales; 6) Instituto Nacional Electoral; 7) nuevas facultades del Congreso de la Unión y de sus cámaras; 8) nuevas atribuciones del Tribunal Electoral del Poder Judicial de la Federación; 9) nuevas causales de nulidad; 10) Fiscalía General de la República; 10) responsabilidades de servidores públicos; 11) gobierno locales y municipales, y 12) transitorios. Por razón natural no me detengo en los temas y subtemas para entrar directamente al asunto cuyo análisis nos ocupa.

La reforma constitucional en materia político-electoral publicada en el Diario Oficial de la Federación del 10 de febrero de 2014, adiciona un párrafo segundo a la fracción I del artículo 115 constitucional para quedar como sigue:

Las Constituciones de los Estados deberán establecer la elección consecutiva para el mismo cargo de presidentes municipales, regidores y síndicos, por un periodo adicional, siempre y cuando el periodo del mandato de los ayuntamientos no sea superior a tres años. La postulación sólo podrá ser realizada por el mismo partido o por cualquiera de los partidos integrantes de la coalición que lo hubieren postulado, salvo que hayan renunciado o perdido su militancia antes de la mitad de su mandato.

Cabe hacer notar que, aun cuando las delegaciones o circunscripciones territoriales administrativas para el gobierno local del Distrito Federal no son municipios pero sí su equivalente, la reforma no se refiere a ellas. Es posible que se trate de una regulación que deba esperar a la reforma en su conjunto del hasta ahora gobierno local de la ciudad capital de la República.

33 2a. ed., México, Trillas-UNAM, 2014. 
Analicemos ahora en primer lugar de manera descriptiva el contenido literal de la reforma en materia de reelección municipal consecutiva. Sus elementos son los siguientes:

1) Las nuevas disposiciones deben constar en las Constituciones de los estados, así como en la legislación secundaria local. Era de suponerse que las leyes generales, tanto en materia de organización electoral como de partidos políticos hubiesen tenido que aludir también, de alguna manera, a la reelección municipal inmediata, pero no lo hicieron.

2) La reelección consecutiva puede ser no solo para el presidente municipal sino también para regidores y síndicos y, se supone, igualmente para sus respectivos suplentes hayan o no ejercido el cargo. Hasta antes de la reforma los suplentes podían ser reelectos siempre y cuando no hubiesen ocupado el cargo.

3) La reelección municipal inmediata solo procederá cuando el periodo para el que sean electos los integrantes del cabildo no sea superior a tres años.

4) En los estados de Coahuila, Hidalgo y Veracruz, donde actualmente el periodo de ejercicio de las autoridades municipales es de cuatro años, es de suponerse que pudiese haber una reforma constitucional local en dichos estados para volver al periodo de tres años y beneficiarse de la reelección inmediata.

5) La postulación de las autoridades municipales a reelegir solo podrá ser realizada por el mismo partido político o coalición que los hubiese postulado en la elección anterior. Esto significa, en principio, que alguno, algunos o todos los integrantes del cabildo en funciones no podrían reelegirse como candidatos independientes o postulados por otro partido o coalición, salvo la prevención que se señala en seguida.

6) Sí podrán ser postulados como candidatos independientes o por otro partido político o coalición siempre que hubiesen renunciado a dicho partido o perdido su militancia antes de la mitad de su mandato.

7) Puesto que las leyes generales no han regulado de manera específica la reelección municipal con mayores detalles, corresponderá a las legislaturas locales hacerlo en las leyes secundarias locales. Sin duda no pocas de las modalidades que aquí se establezcan que serán evaluadas en su momento, en su constitucionalidad y convencionalidad, por los tribunales nacionales e internacional competentes. 


\section{Las leyes generales}

El 23 de mayo de 2014 fueron publicadas en el Diario Oficial de la Federación la Ley General de Instituciones y Procedimientos Electorales, la Ley General de Partidos Políticos y la Ley General de Delitos Electorales. Ninguno de los ordenamientos anteriores formula mención expresa alguna respecto de la reelección municipal; ni siquiera el Título Tercero del Libro Segundo de la LGIPE, relativo a la elección de gobernadores, legislaturas locales y ayuntamientos, entre otros temas, alude a la reelección inmediata de autoridades municipales.

En la misma fecha fueron publicadas adiciones y reformas a los siguientes ordenamientos: Ley General del Sistema de Medios de Impugnación en Materia Electoral, Ley Orgánica del Poder Judicial de la Federación y Ley Federal de Responsabilidades Administrativas de los Servidores Públicos, cuyo contenido no se relaciona de manera expresa con el tema que ahora nos ocupa.

\section{Reflexión final}

La reelección municipal inmediata, en los términos que ahora es regulada en nuestro país después de la reforma en comento, tiene dos características básicas: solo puede darse por dos periodos consecutivos de tres años, además de que para evitar el transfuguismo se impone la misma restricción que a los legisladores, restricción que por razón natural solo puede ser aplicable a los candidatos originalmente postulados por un partido político o coalición. Desde luego, como ya ha sucedido en Zacatecas, ${ }^{34}$ el transfuguismo no podrá ser evitado una vez transcurrido el periodo de intervalo, sin que esto anuncie que las probabilidades de triunfo del candidato que cambia de opción partidista o adopta la de candidato independiente, puedan aumentar o disminuir, toda vez que están sujetas también a otros factores.

El periodo de cuatro años para las autoridades municipales es una práctica política y constitucional que no alcanzó a fructificar en México y que con la actual reforma es eliminada en las entidades donde

34 Cfr. Soto Acosta, Leticia Catalina, "Candidaturas independientes. Experiencia Zacatecas”, Revista Mexicana de Derecho Electoral, México, núm. 5, enero-junio de 2014, pp. 337 y ss. 
existía. Ciertamente, de haberse mantenido con la nueva disposición de reelección inmediata por un periodo hubieran podido existir autoridades municipales de ocho años, más aún, algunos estados pudieron haber ampliado el periodo municipal a cinco o seis años que, con la reelección inmediata por una vez, hubiera podido dar cabildos municipales hasta de doce años; situación contraria a los periodos de los gobernadores, para quienes se mantiene la no reelección, que son de seis años, pero que estuvo prevista en la iniciativa del PAN y del PRD. En México, de manera consecutiva solo los senadores podrán mantenerse doce años en el cargo, a partir de 2018 .

El escepticismo ciudadano respecto de los beneficios de la reelección inmediata en cualquier cargo público revelado por las encuestas elaboradas por el Instituto de Investigaciones Jurídicas de la UNAM citadas, en mi opinión, está asociado necesariamente al carácter testimonial que durante muchos años tuvieron las elecciones en nuestro país y al discurso legitimador del partido hegemónico. Además, la pérdida de las mayorías calificada y absoluta del PRI en la Cámara de Diputados data apenas de 1988 y 1997, respectivamente; en la Cámara de Senadores, de 1994 y 2000, respectivamente; la alternancia en el Ejecutivo federal, de 2000, y la doble alternancia en éste, de 2012.

Consecuentemente, es un largo camino aún el que deberá recorrerse para reducir los periodos de presidente y gobernador, a efecto de permitir su evaluación y sanción por parte de un electorado que consciente de su poder de voto, preparado e informado, sepa encontrar en la reelección inmediata de los mismos un mecanismo de control del poder. Salvo que una regresión autoritaria, como ya ha sucedido una vez en México y en otros países de América Latina, permita dicho tránsito mucho antes. Entre tanto, el aprendizaje o mejoramiento de una cultura democrática por parte de la ciudadanía nacional pasará en los próximos años por la prueba de la reelección municipal inmediata y — sobre todo en los municipios - de las candidaturas independientes.

\section{Bibliografía}

ArIas De la Mora, Roberto, Democracia y gestión pública municipal, México, Instituto Nacional de Administración Pública, 2013.

CARPIzo, Jorge, El presidencialismo mexicano, 4a. ed., México, Siglo XXI editores, 1984. 
Castellanos Hernández, Eduardo de Jesús (autor) y Zertuche MuÑoz, Fernando (coord.), Sistemas electorales de México y Legislación y estadísticas electorales. 1814-1997, serie IV, vol. III, ts. 1 y 2, respectivamente, de la Enciclopedia Parlamentaria de México, México, Cámara de Diputados, LVI Legislatura del H. Congreso de la Unión, 1997.

Castellanos Hernández, Eduardo de Jesús, Las reformas de 1996, México, Centro de Investigación Científica “Ing. Jorge L. Tamayo”, 1998.

-_- Para entender la democracia. Teoría política, formas de gobierno, sistemas electorales, sistemas de partidos y calidad de la democracia, México, edición del autor, 2008.

- - - (coord.), Antecedentes históricos y Constituciones políticas de los Estados Unidos Mexicanos, 4a. ed., México, Secretaría de Gobernación, 2011.

-_-, Nuevo derecho electoral mexicano, 2a. ed., México, UNAM-Trillas, 2014.

Cruz Parcero, Luz María, El laberinto de la representación. Una mirada desde México, México, Tribunal Electoral del Poder Judicial de la Federación, 2012.

Diseño de sistemas electorales: el nuevo manual de IDEA Internacional, México, Institute for Democracy and Electoral Assistance-Tribunal Electoral del Poder Judicial de la Federación, Instituto Federal Electoral, 2006.

Fernández Ruiz, Jorge, Las elecciones municipales, México, Tribunal Electoral del Poder Judicial de la Federación, 2010.

Flores, Julia Isabel et al., "Reelección y democracia: cambios en los valores de la población", Revista Mexicana de Derecho Electoral, México, núm. 2, julio-diciembre de 2012.

"Gobernanza eficaz. La administración pública y la responsabilidad social en el México actual”, Revista de Administración Pública 133, México, vol. XLIX, núm. 1, enero-abril de 2014.

Manual para el Diseño de Sistemas Electorales de IDEA Internacional, México, Institute for Democracy and Electoral Assistance-Tribunal Electoral del Poder Judicial de la Federación-Instituto Federal Electoral, 2000.

Moreno Espinosa, Roberto (coord.), Gobierno, gestión y profesionalización en el ámbito local ante los grandes retos de nuestro tiempo, México, Universidad Autónoma del Estado de México, Centro Universitario UAEM Amecameca, 2011.

Nohlen, Dieter, Sistemas electorales en su contexto, México, UNAMSCJN-BUAP, 2008. 
-_-, Ciencia política comparada. El enfoque histórico-empírico, Bogotá, Benemérita Universidad Autónoma de Puebla-Universidad del Rosario, 2013.

Revista Mexicana de Derecho Electoral, México, núm. 2, julio-diciembre de 2012.

Revista Mexicana de Derecho Electoral, México, núm. 5, enero-junio de 2014.

SfEZ, Lucien, Laaministration prospective, París, Librairie Armand Colin, 1970.

Páginas web

www.diputados.gob.mx.

www.senado.gob.mx.

www.ordenjuridico.gob.mx.

www.sil.gobernacion.gob. $m x$.

www.pactopormexico.org.

http://www.senado.gov.co/images/stories/Informacion_General/Refor mas_constitucion_politica_de_colombia.pdf.

http://www.cc.gob.gt/DocumentosCC/ConstitucionGuatemala.pdf. http://www.asamblea.gob.ni/Informacion\%20Legislativa/. 